\title{
The Relationship between Customers' Switching Cost and Repurchase Intention: The Moderating Role of Satisfaction
}

\author{
Shueh-Chin Ting \\ Department of Education, National University of Tainan, Tainan, Taiwan \\ Email: tingsc@ms49.hinet.net
}

Received 19 June 2014; revised 16 July 2014; accepted 12 August 2014

Copyright (C) 2014 by author and Scientific Research Publishing Inc.

This work is licensed under the Creative Commons Attribution International License (CC BY). http://creativecommons.org/licenses/by/4.0/

cC) (7) Open Access

\begin{abstract}
Past researches suggest that switching cost could retain customers and increase their repurchase intention; however, this study does not completely agree with this statement. By treating customers' satisfaction as the moderating variable, this study attempts to identify the relationship between switching cost and customers' repurchase intention. The research subjects of this study were consumers of mobile phone communication service in Taiwan; the customer satisfaction was divided into high, medium and low degrees. The results indicated that upon different degrees of customer satisfaction, there are different relationships between switching cost and customers' repurchase intention. Specifically, with high or low customer satisfaction, there is no significant relationship between switching cost and customers' repurchase intention. Only with medium customer satisfaction, there is a significant and positive relationship between switching cost and customers' repurchase intention. Therefore, the enterprises should take care that customer satisfaction can not be too low; otherwise, only relying on switching cost, they will not be able to keep the customers.
\end{abstract}

\section{Keywords}

Consumer, Customer, Moderating, Repurchase Intention, Satisfaction, Switching Cost

\section{Introduction}

Since consumers' demands vary largely and market competition is severe, in order to satisfy consumers' various needs and obtain profits in the competitive market, many enterprises intend to introduce the latest and the best services to retain customers. Switching cost is an important strategy to keep customers [1]; it is a universal phe- 
nomenon and often exists in different industries and different consumption fields [2]. It is useful for organizational operation. For instance, it can enhance consumers' dependence on organizations [3], increase consumers' perceived risk of switching [4], reduce the negative effect of unstable service [5] and increase consumers' repurchase intention [6].

The relationship between switching cost and repurchase intention is disputable. Most literatures suggest a positive relationship between switching cost and repurchase intention [7]-[9]. However, [1] indicated that there was no significant relationship between switching cost and repurchase intention. This study suggests that there may be moderating variables between switching cost and repurchase intention. Regarding moderating relationship, past researches mostly focus on the moderating effect of switching cost between satisfaction and repurchase intention [6] [10] [11]. However, there are scanty studies on the moderating role of satisfaction (the moderating effect of satisfaction between switching cost and repurchase intention). This study aims to probe into the role of satisfaction, the personal emotional variable, between cognition (switching cost) and behavior (repurchase intention). Thus, the purpose of this study is to find out if satisfaction will moderate the relationship between switching cost and repurchase intention. This study argues that only medium customer satisfaction will lead to more significant relationship between switching cost and repurchase intention. Empirical study is conducted to verify this argument.

\section{Literature Review and Hypothesis Development}

Content of literature review is divided into two units: "switching cost" and "moderating role of satisfaction in relationship between switching cost and repurchase intention”.

\subsection{Switching Cost}

Switching cost refers to the risk, investment and loss of customers having to take because of changing service providers. Some studies have divided switching cost as the loss of finance, time, psychology and relationship [12]. By literature review and focus group interview, [6] generalized eight dimensions, namely risk cost, evaluation cost, learning cost , setup cost, benefit loss cost, monetary loss cost, personal relationship loss cost and brand relationship loss cost, and further divided them into three categories (procedural switching cost, financial switching cost and relational switching cost), as shown in Table 1. Procedural switching cost involves the expenses of time and efforts. Financial switching cost involves the loss of financially quantified resources. Relational switching cost involves psychological or emotional discomfort caused by the loss of identification and the breaking of the relationship bonding. Procedural switching cost includes risk cost, evaluation cost, learning cost and setup cost. Financial switching cost includes benefit loss cost and monetary loss cost. Relational switching cost includes personal relationship loss cost and brand relationship loss cost. Risk cost refers to the cost of possible negative results when consumers switch to the unfamiliar service providers. Evaluation cost means the cost of time and efforts to collect and analyze information for switching decision making. Learning cost means the cost of time and efforts to acquire new skills and knowledge in order to effectively use the services provided by new service providers. Setup cost refers to the cost of time and efforts when start to use the services of new service providers. Benefit loss cost means the loss of financial benefits provided by the original companies after the switching, such as the accumulated points or discount. Monetary loss cost means the cost promised or provided at one time before receiving the services of the original companies, such as payment for signing the contract and

\begin{tabular}{|c|c|}
\hline Main categories of switching cost & Sub-categories of switching cost \\
\hline Procedural switching cost & $\begin{array}{l}\text { 1) Risk cost } \\
\text { 2) Evaluation cost } \\
\text { 3) Learning cost } \\
\text { 4) Setup cost }\end{array}$ \\
\hline Financial switching cost & $\begin{array}{l}\text { 1) Benefit loss cost } \\
\text { 2) Monetary loss cost }\end{array}$ \\
\hline Relational switching cost & $\begin{array}{l}\text { 1) Personal relationship loss cost } \\
\text { 2) Brand relationship loss cost }\end{array}$ \\
\hline
\end{tabular}

Source: Burnham et al. (2003). 
forfeit for breach of contract. Personal relationship loss cost refers to the loss incurred by losing consumers' personal relationship with the past service personnel after switching the enterprises. Brand relationship loss cost refers to the loss of consumers' benefits, which derive from the positive image of the past companies, after switching the enterprises.

This study suggests that the classification of [6] is clear and complete, and thus treats it as the criterion of categorization of switching cost.

\subsection{Moderating Role of Satisfaction in Relationship between Switching Cost and Repurchase Intention}

Switching cost can form a lock-in effect on consumers [13], and the sources of the effect are likely to be risk cost, evaluation cost, learning cost, setup cost, benefit loss cost, monetary loss cost, personal relationship loss cost or brand relationship loss cost, which all can maintain the relationship between consumers and current service providers. Switching cost is the important factor to "restrain” customers' switching behavior [6]. When customers perceive high switching cost, they are less likely to have switching behavior.

Based on the above, many studies have suggested that since switching cost can restrain customers' switching behavior, it will be able to reduce the probability of customers' switching behavior and increase their repurchase intention. For consumers, when they perceive high cost to stop current relationship with service providers, their repurchase intention will certainly be increased. Thus, there is a positive relationship between switching cost and repurchase intention. However, the view is not supported by [1]. This study suggests that the relationship between switching cost and repurchase intention can be moderated by satisfaction, and it is necessary to explore it by high, medium and low degrees of satisfaction.

First, we argue for high customer satisfaction. [14] suggested that when the enterprises increase the prices, consumers' repurchase intention would be lower. However, the negative effect of increase of prices on consumers with high satisfaction is lower. In other words, consumers' high satisfaction will reduce the negative effect of the enterprises' increase of prices on consumers' repurchase intention. Increase of prices is negative information for consumers. Referring to [14], this study infers that consumers with high satisfaction, in comparison to those with low satisfaction, are less sensitive to negative information. In addition, [15] suggested that satisfaction would positively influence loyalty. Many researches [1] [16] have indicated a positive relationship between satisfaction and repurchase intention. Based on the findings, it is inferred that consumers with high satisfaction have less intention to switch the enterprises, and thus, they will not pay attention to and consider switching cost. This study concludes that customers with high satisfaction are less sensitive to, do not pay attention to, and do not consider switching cost. With high satisfaction, switching cost still exists. However, the customers are less sensitive to, do not pay attention to, and do not consider switching cost, which will not significantly influence their repurchase intention. Therefore, with high satisfaction, the relationship between switching cost and repurchase intention is weak.

H1: For customers with high satisfaction, perception of switching cost does not significantly influence repurchase intention.

When satisfaction is low, this study suggests that customers will not rationally consider the issue of switching cost. The view is based on the statement on consumers' information processing suggested by [17] and [18]. [17] suggested that consumers' information processing can be instinctive or systematic. [18] interpreted consumers' information processing by two process theory, and it includes experiential and rational ways. Instinctive method suggested by [17] and experiential way indicated by [18] are more emotional. Systematic information processing suggested by [17] and rational one indicated by [18] are non-emotional. Switching cost consumers facing before switching can be viewed as a kind of information. How to process this information is related to consumers' satisfaction. When the consumers have lower satisfaction, it will result in their negative emotion and stronger switching motive. With negative emotion, consumers will not carefully consider switching cost and tend to be irrational. They usually stop current relationship by emotional reaction and switch to new service providers. Thus, for customers with low satisfaction, the relationship between switching cost and repurchase intention is weak.

H2: For customers with low satisfaction, perception of switching cost does not significantly influence repurchase intention.

This study suggests that only when satisfaction is medium, switching cost is the most influential on repur- 
chase intention. Since switching cost is caused when customers switch service providers, without the switching, there will be no switching cost [6]. However, the problem of switching cost still exists even without the switching. The effect of switching cost on customers' repurchase intention relies on customers' attention to switching cost. When customers are highly satisfied, they do not have to switch the product or service providers, and switching cost is useless information, which will not be considered by them. With low satisfaction, customers will not pay attention to switching cost since they will impulsively make the decision to switch the product or service providers. Thus, switching cost cannot retain customers.

However, when customers' satisfaction is medium, customers' reaction is between high and low satisfaction. The reaction is that customers have the switching idea, but they will not be too emotional. Consumers can rationally consider the issue and will not make the decision impulsively. Switching cost will be the key in their consideration. There is closer and positive relationship between switching cost and repurchase intention. This relationship demonstrated in past researches is the outcome of customers' medium satisfaction.

H3: For customers with medium satisfaction, perception of switching cost significantly and positively influences repurchase intention.

\section{Research Method}

\subsection{Research Framework}

This study wants to verify whether satisfaction moderates the influence of switching cost on repurchase intention. The research variables are organized in research framework shown in Figure 1.

\subsection{Sampling and Samples}

The subjects of this study were the consumers who use mobile phone communication service in Taiwan. The main reasons to choose the telecommunications industry are below. In Taiwan, many companies provide mobile phone communication service, including Chunghwa Telecom, Taiwan Mobile, FETnet, TransAsia Telecom, Vibo Telecom, Asia Pacific Telecom, etc. The competition is severe and customers often switch their service providers. In addition, in Taiwan, mobile phone communication is popular and almost everyone, including elementary school students, has a mobile phone. Thus, mobile phone communication service is important for consumers in Taiwan. Moreover, mobile phone communication service in Taiwan is based on contracts, and when signing the contracts, the consumers must agree with the years of use. There is the monetary loss and forfeit for breach of contract. Therefore, in Taiwan, there is switching cost in mobile phone communication service.

The questionnaires were distributed to consumers using mobile phone communication service in southern Taiwan. A total of 400 questionnaires were distributed by means of actually visiting the consumers, and 375 were retrieved. After eliminating 25 invalid questionnaires with incomplete or highly inconsistent answers (imprecise answers), there were 350 valid questionnaires.

As to sample structure, the percentages of males (51\%) and females (49\%) are close; most of the subjects are young people aged 21 - 30 (35.4\%), followed by those aged 31 - 40 (30.8\%); most of them are graduated from universities (57.3\%); they mostly work in business and service industry (67.8\%); their monthly personal income is mostly NTD 20,001 - 40,000 (60.2\%).

\subsection{Operational Definitions of Variables and Measurement}

Variables in this study include switching cost (procedural switching cost, financial switching cost and relational switching cost), repurchase intention and satisfaction. Operational definitions of variables are shown in Table 2.

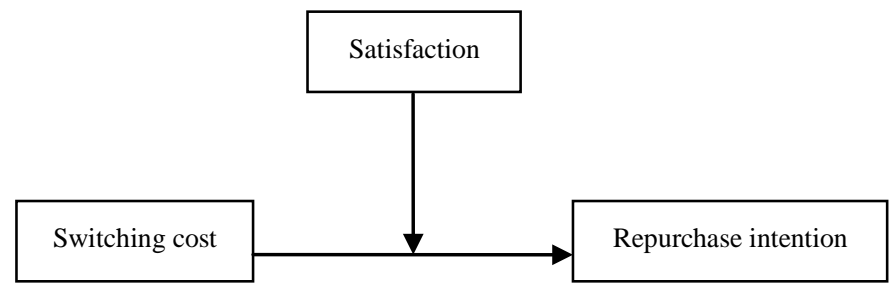

Figure 1. Research framework. 
Table 2. Operational definitions of variables and items.

\begin{tabular}{lll}
\hline Constructs/dimensions & Operational definitions & Items \\
\hline
\end{tabular}

Switching cost

Procedural switching cost

Risk cost

Evaluation cost

Learning cost

Setup cost

Benefit loss cost

Monetary loss cost

Personal relationship loss cost
Consumers' cost to worry about the uncontrollable and possible costs after switching the company of mobile phone communication service.

Consumers' cost to understand and compare the companies of mobile phone communication service.

Consumers' cost to learn and adapt to the services provided by new company of mobile phone communication service.

Consumers' cost of first use of services provided by new company of mobile phone communication service.

Consumers lose the original benefits after switching to new company of mobile phone communication service.

Consumers' payment before experiencing the services provided by current company of mobile phone communication service.

Consumers lose the benefits upon the interpersonal relationship in current company of mobile phone communication service.
A1. I worry that the service provided by other communication service company might not match my expectation.

A2. I worry that there can be potential cost or expense after switching to new company of communication service.

A3. I worry that there can be unexpected trouble after switching to new communication service company.

B1. I do not have sufficient time to understand the information of other communication service companies.

B2. I must spend plenty of time or efforts to evaluate other communication service companies.

B3. It is difficult to compare current company with others.

C1. It takes efforts to adapt the services provided by a communication service company.

C2. After the switching, it still takes time and efforts to learn the service of new communication service company.

C3. It is easy to learn the services of other communication service companies (reverse item).

D1. It will spend plenty of time and efforts to use the service of new communication service company at the beginning.

D2. It takes time to construct the relationship with new communication service company.

D3. It requires complicated steps to switch to other communication service companies.

E1. If I switch to other communication service company, I will lose the accumulated benefits in current communication service company.

E2. If I switch to other communication service company, my efforts accumulated will be in vain.

E3. If I switch to other communication service company, I will lose the benefits as a long-term user.

F1. I think I will lose some money by switching to other companies before the due of the contract.

F2. I must lose some money in order to switch to other communication service companies.

F3. I think I will not lose a lot by switching to other communication service companies before the due of the contract (reverse item).

G1. If I switch to other communication service company, I will miss the original service personnel.

G2. The service personnel of current communication service company are more comfortable for me than those in other communication service companies.

G3. I enjoy talking or chatting with current service personnel. 
Brand relationship loss Consumers lose the benefits cost with current brand.
Consumers’ overall psychological

Satisfaction

Repurchase intention reaction toward the services provided by current company of mobile phone communication service.

Consumers' intention to continue using the services provided by current company of mobile phone communication service.
H1. I like the public image of current communication service company.

H2. I do not care about the name of current communication service company (reverse item).

H3. I think the current communication service company does create positive corporate image.

S1. I hate choosing current communication service company (reverse item).

S2. I am glad that I chose current communication service company.

S3. The communication service company I chose satisfies many of my needs.

S4. Choosing this communication service company is the right decision.

$\mathrm{R} 1$. In the following year, I will be very likely to continue using the service provided by current company of communication service.

R2. If current contract is due, I will possibly extend it.

R3. If current contract is due, I will immediately switch to other communication service companies (reverse item).

The items of switching cost and satisfaction are adapted from [6] and the items of repurchase intention are adapted from [1].

There are 31 items (see Table 2), including 24 items for measuring switching cost: procedural switching cost (12 items), financial switching cost (6 items) and relational switching cost (6 items); 3 items are for measuring repurchase intention and 4 items are for measuring satisfaction. The scoring is based on Likert 5-point scale (1 denotes strongly disagree; 2 denotes disagree; 3 is no comment; 4 is agree; 5 is strongly agree). A higher score means that variables are more significant. Procedural switching cost is measured by risk cost, evaluation cost, learning cost, and setup cost. Financial switching cost is measured by benefit loss cost and monetary loss cost. Relational switching cost is measured by personal relationship loss cost and brand relationship loss cost. The means of each switching cost measures stand for the scores of procedural switching cost, financial switching cost and relational switching cost. Repurchase intention and satisfaction are originally in one-order measurement model. After condensation, switching cost is also measured by one-order model.

\subsection{Reliability and Validity of Measurement}

Before the validation of hypotheses, this study tested the reliability and validity of the scale. As to the test of reliability and convergent validity of measurement, this study adopted Confirmatory Factor Analysis to conduct three-factor one-order model analysis on switching cost, repurchase intention and satisfaction. The results are shown in Table 3. The result of Confirmatory Factor Analysis shows that the chi-square ratio of three-factor one-order model is 1.7, RMSEA $=0.045, \mathrm{CFI}=0.99$, $\mathrm{RMR}=0.023$, GFI $=0.97$ and AGFI $=0.95$, indicating a good fit of the model.

As to reliability of measurement, composite reliabilities of switching cost, repurchase intention and satisfaction are $0.81,0.83$ and 0.88 , indicating that the reliability of measurement is good.

Regarding convergent validity of measurement, besides good model fit of three-factor one-order model, all items are significant $(p<0.001)$. As to loading of the factors design, in switching cost, factor loading of procedural switching cost, financial switching cost and relational switching cost are $0.68,0.76$, and 0.85 . Three items of repurchase intention are $0.68,0.85$, and 0.81 . Four items of satisfaction are $0.68,0.79,0.90$ and 0.85 . They are above the standard 0.50. Moreover, average variance extracted of switching cost, repurchase intention and satisfaction are $0.59,0.62$ and 0.65 . They are higher than the standard 0.50. According to the suggestion of [19], convergent validity of the measurement in this study is good.

Regarding discriminant validity of measurement, this study tested discriminant validity according to the criterion suggested by [20]. Correlation coefficients of two constructs tested must be lower than square root of their average variance extracted. According to Table 4, correlation coefficient between switching cost and repurchase 
Table 3. Convergent validity and reliability analysis of measurement.

\begin{tabular}{|c|c|c|c|c|}
\hline Constructs & Codes of items & Factor loading & Average variance extracted & Composite reliability \\
\hline \multirow[t]{3}{*}{ Switching cost } & proc & $0.68^{* * *}$ & 0.59 & 0.81 \\
\hline & fina & $0.76^{* * *}$ & & \\
\hline & rela & $0.85^{* * *}$ & & \\
\hline \multirow[t]{3}{*}{ Repurchase intention } & rep1 & $0.68^{* * *}$ & 0.62 & 0.83 \\
\hline & rep2 & $0.85^{* * *}$ & & \\
\hline & rep3 & $0.81^{* * *}$ & & \\
\hline \multirow[t]{4}{*}{ Satisfaction } & sat1 & $0.68^{* * *}$ & 0.65 & 0.88 \\
\hline & sat2 & $0.79^{* * * *}$ & & \\
\hline & sat3 & $0.90^{* * * *}$ & & \\
\hline & sat4 & $0.85^{* * *}$ & & \\
\hline \multirow{2}{*}{\multicolumn{5}{|c|}{$\begin{array}{c}\text { Three-factor one-order correlation model } \\
\chi^{2}=54.45, \mathrm{df}=32, p=0.008, \mathrm{RMSEA}=0.045, \mathrm{CFI}=0.99, \mathrm{RMR}=0.023, \mathrm{GFI}=0.97, \mathrm{AGFI}=0.95\end{array}$}} \\
\hline & & & & \\
\hline \multicolumn{5}{|l|}{ Note: ${ }^{* * *} p<0.001$} \\
\hline \multicolumn{5}{|c|}{ Table 4. Discriminant validity analysis of measurement. } \\
\hline & \multicolumn{2}{|c|}{ Switching cost } & Repurchase intention & Satisfaction \\
\hline Switching cost & \multicolumn{2}{|c|}{0.77} & & \multirow[b]{3}{*}{0.81} \\
\hline Repurchase intention & \multicolumn{2}{|c|}{0.16} & 0.79 & \\
\hline Satisfaction & \multicolumn{2}{|c|}{0.20} & 0.35 & \\
\hline
\end{tabular}

Note: figures of diagonal line are square root of average variance extracted and figures of non-diagonal line are correlation coefficients.

intention is 0.16 , which is lower than square root of average variance extracted of switching cost (0.77) and lower than square root of average variance extracted of repurchase intention (0.79). Correlation coefficient between switching cost and satisfaction is 0.20 , which is lower than square root of average variance extracted of switching cost (0.77) and lower than square root of average variance extracted of satisfaction (0.81). Correlation coefficient between satisfaction and repurchase intention is 0.35 , which is lower than square root of average variance extracted of satisfaction (0.81) and lower than square root of average variance extracted of repurchase intention (0.79). Thus, based on the suggestion of [20], discriminant validity of measurement in this study is good.

\section{Research Results}

Measurement of satisfaction is based on 5-point scale. According to the scores of satisfaction, upon 3.5 and 2.5 as the separation points, the subjects were divided into three groups (high, medium and low satisfaction groups). High satisfaction group is the subjects with scores of satisfaction above or equal to 3.5 (120 subjects); medium satisfaction group is the subjects with scores of satisfaction above 2.5 and below 3.5 (141 subjects); low satisfaction group is the subjects with scores of satisfaction lower and equal to 2.5 (89 subjects). This study respectively conducted regression analysis on the three groups to find out whether switching cost will influence customers' repurchase intention. Switching cost is the independent variable, and customers' repurchase intention is the dependent variable. Result of the hypothesis test is shown in Table 5 . As seen, for the subjects of high satisfaction group, standardized regression coefficient is only 0.002 and $t$ is 0.024 , which does not reach significance level of $p<0.05$. Thus, for the subjects of high satisfaction group, switching cost will not significantly influence customers' repurchase intention. Thus, H1 is supported. For the subjects of low satisfaction group, the result is the same as those of high satisfaction group. Switching cost will not significantly influence customers' repurchase intention (standardized regression coefficient is 0.056 and $t$ is 0.522 , which does not reach significance 
Table 5. Regression analysis of customers' repurchase intention on switching cost.

\begin{tabular}{cccccc}
\hline & Number of samples & $\begin{array}{c}\text { Standardized regression } \\
\text { coefficient }\end{array}$ & $\mathrm{t}$ & $p$ & $\begin{array}{c}\text { Validation of } \\
\text { hypotheses }\end{array}$ \\
\hline High satisfaction group & 120 & 0.002 & 0.024 & 0.981 & H1 supported \\
Medium satisfaction group & 141 & 0.200 & 2.406 & 0.017 & H3 supported \\
Low satisfaction group & 89 & 0.056 & 0.522 & 0.603 & H2 supported \\
\hline
\end{tabular}

level of $p<0.05)$. Thus, H2 is supported. Only medium satisfaction group reveals significant influence. Standardized regression coefficient is 0.200 and $t$ is 2.406 , which reaches significance level of $p<0.05$. Thus, for the subjects of medium satisfaction group, switching cost will significantly and positively influence customers' repurchase intention. Thus, H3 is supported. Based on the above, regarding the hypothesis that switching cost significantly and positively influences customers' repurchase intention, according to the findings of this study, only the subjects in medium satisfaction group are supported. High and low satisfaction groups do not reveal the significant relationship. It matches the expectation of this study. Thus, three hypotheses of this study are supported. The findings can explain why past researches did not demonstrate consistent results on significant and positive effect of switching cost on customers' repurchase intention. Without realizing the effect of satisfaction and including the subjects of different degrees of satisfaction in the analysis, different results would be obtained according to the subjects' satisfaction distribution. Specifically, when most of the subjects have medium satisfaction, it is more likely to demonstrate the significant and positive effect of switching cost on customers' repurchase intention. It is the contribution of this study.

\section{Conclusion}

There are many kinds of switching cost, and each kind can relatively restrain customers' switching behavior and increase their repurchase intention. It is the view in the past researches. Switching cost is also the practical strategy used by many enterprises to keep the customers. However, this study queries this view and in some researches, the relationship between switching cost and customers' repurchase intention is insignificant. This study proposed that customer satisfaction was a factor which should be concerned. This study treated the consumers of mobile phone communication service in Taiwan as the subjects, and found that consumers with different degrees of satisfaction would lead to different results. For consumers with high and low satisfaction, switching cost does not significantly influence customers' repurchase intention, and only for the consumers with medium satisfaction, switching cost significantly and positively influences customers' repurchase intention. It means that the past view, switching cost will positively influence customers' repurchase intention, is not entirely precise. Specifically, the view is correct only for consumers with medium satisfaction. As suggested in the literature review, consumers with high satisfaction do not have switching ideas, so switching cost is unrelated to them, and it is not necessary to consider switching cost. Consumers with high satisfaction have repurchase intention that is because of high satisfaction instead of switching cost. On the other hand, consumers with low satisfaction have negative emotion. Thus, they rashly accept switching cost or do not carefully consider switching cost in stopping the current relationship. In other words, with low satisfaction, switching cost cannot effectively restrain consumers' switching behavior. In addition, consumers with medium satisfaction are neither very satisfied nor very unsatisfied. They do not have negative emotion, and do not have to switch the enterprises; thus, they tend to consider switching cost carefully. In the case of medium satisfaction, with low switching cost, the switching will be easier. With high switching cost, the switching barrier will be increased. Switching cost becomes a key to switch. Thus, for consumers with medium satisfaction, the positive relationship between switching cost and repurchase intention is more significant.

\section{Suggestions}

\subsection{Suggestion for Future Studies}

Switching cost, customers' repurchase intention, and customer satisfaction are three variables in this study and these variables are perception variables of consumers. The questionnaires should thus be answered by the consumers, and this study does so. However, since the answer of a questionnaire is from single source (consumers), 
there can be the problem of common method variance. Future studies can consider inviting the enterprises to provide some answers for a questionnaire in order to avoid the problem of common method variance.

As to the relationship between switching cost and repurchase intention, this study probes into the moderating role of satisfaction, and the empirical subject is only one industry: mobile phone communication service in telecommunication industry. Currently, the switching barrier of mobile phone communication service is not high. When consumers are unsatisfied, they are more likely to neglect switching cost and switch the communication service companies. Thus, for consumers with low satisfaction, will the relationship between switching cost and repurchase intention be insignificant in all industries? It will rely on further research. This study suggests that in the industries with high switching cost, consumers with low satisfaction tend to endure and be rational. There is a positive relationship between switching cost and repurchase intention. However, in industries with low switching cost, consumers with low satisfaction will neglect switching cost, and they tend to be impulsive. There is an insignificant relationship between switching cost and repurchase intention. However, the statements should be demonstrated by future researchers.

\subsection{Suggestion for the Enterprises}

According to the findings of this study, at least for mobile phone communication service of telecommunication industry, with the increase of customer satisfaction to some degree, the existence of switching cost will be not indispensable to keep customers. With the decrease of customer satisfaction to some degree, switching cost will be ineffective to lock-in customers. Thus, the enterprises should take care that customer satisfaction can not be too low; otherwise, only relying on switching cost, they will not be able to keep the customers. Therefore, customer satisfaction, in comparison to switching cost, should be more valued. To effectively elevate customers' repurchase intention, the enterprises should first enhance customer satisfaction, after reaching basic customer satisfaction, and then implement the strategies of increasing switching cost.

\section{References}

[1] Jones, M.A., Mothersbaugh, D.L. and Beatty, S.E. (2000) Switching Barriers and Repurchase Intentions in Services. Journal of Retailing, 76, 259-274. http://dx.doi.org/10.1016/S0022-4359(00)00024-5

[2] Klemperer, P. (1995) Competition When Consumers Have Switching Costs: An Overview with Application to Industrial Organization, Macroeconomics and International Trade. Review of Economic Studies, 62, 515-539. http://dx.doi.org/10.2307/2298075

[3] Morgan, R.M. and Hunt, S.D. (1994) The Commitment-Trust Theory of Relationship Marketing. Journal of Marketing, 58, 20-38. http://dx.doi.org/10.2307/1252308

[4] Colgate, M. and Lang, B. (2001) Switching Barriers in Consumer Markets: An Investigation of the Financial Services Industry. Journal of Consumer Marketing, 18, 332-347. http://dx.doi.org/10.1108/07363760110393001

[5] Bell, S.J., Auh, S. and Smalley, K. (2005) Customer Relationship Dynamics: Service Quality and Customer Loyalty in the Context of Varying Levels of Customer Expertise and Switching Costs. Journal of the Academy of Marketing Science, 33, 169-183. http://dx.doi.org/10.1177/0092070304269111

[6] Burnham, T.A., Frels, J.K. and Mahajan, V. (2003) Consumer Switching Costs: A Typology, Antecedents, and Consequence. Journal of the Academy of Marketing Science, 31, 109-126. http://dx.doi.org/10.1177/0092070302250897

[7] Jones, M.A., Mothersbaugh, D.L. and Beatty, S.E. (2002) Why Customers Stay: Measuring the Underlying Dimensions of Services Switching Costs and Managing Their Differential Strategic Outcomes. Journal of Business Research, 55, 441-450. http://dx.doi.org/10.1016/S0148-2963(00)00168-5

[8] Lu, T., Tu, R. and Jen, W. (2011) The Role of Service Value and Switching Barriers in an Integrated Model of Behavioural Intentions. Total Quality Management \& Business Excellence, 22, 1071-1089. http://dx.doi.org/10.1080/14783363.2011.614867

[9] Tsai, H.T., Huang, H.C., Jaw, Y.L. and Chen, W.K. (2006) Why On-Line Customers Remain with a Particular E-Retailer: An Integrative Model and Empirical Evidence. Psychology \& Marketing, 23, 447-464. http://dx.doi.org/10.1002/mar.20121

[10] Kim, G., Shin, B. and Lee, H.G. (2006) A Study of Factors That Affect User Intentions toward Email Service Switching. Information \& Management, 43, 884-893. http://dx.doi.org/10.1016/j.im.2006.08.004

[11] Shin, D.H. and Kim, W.Y. (2008) Forecasting Customer Switching Intention in Mobile Service: An Exploratory Study of Predictive Factors in Mobile Number Portability. Technological Forecasting \& Social Change, 75, 854-874.

http://dx.doi.org/10.1016/j.techfore.2007.05.001 
[12] Whitten, D. and Wakefield, R.L. (2006) Measuring Switching Costs in IT Outsourcing Services. Journal of Strategic Information Systems, 15, 219-248. http://dx.doi.org/10.1016/j.jsis.2005.11.002

[13] Bendapudi, N. and Berry, L.L. (1997) Customers’ Motivations for Maintaining Relationships with Service Providers. Journal of Retailing, 73, 15-37. http://dx.doi.org/10.1016/S0022-4359(97)90013-0

[14] Homburg, C., Hoyer, W.D. and Koschate, N. (2005) Customers' Reactions to Price Increases: Do Customer Satisfaction and Perceived Motive Fairness Matter? Journal of the Academy of Marketing Science, 33, 36-49. http://dx.doi.org/10.1177/0092070304269953

[15] Ibáñez, V.A., Hartmann, P. and Calvo, P.Z. (2006) Antecedents of Customer Loyalty in Residential Energy Markets: Service Quality, Satisfaction, Trust and Switching Costs. Service Industries Journal, 26, 633-650. http://dx.doi.org/10.1080/02642060600850717

[16] Lin, H.H. and Wang, Y.S. (2006) An Examination of the Determinants of Customer Loyalty in Mobile Commerce Contexts. Information \& Management, 43, 271-282. http://dx.doi.org/10.1016/j.im.2005.08.001

[17] Chaiken, S. (1980) Heuristic Versus Systematic Information Processing and the Use of Source Versus Message Cues in Persuasion. Journal of Personality and Social Psychology, 39, 752-766. http://dx.doi.org/10.1037/0022-3514.39.5.752

[18] Chaiken, S. and Trope, Y. (1999) Dual-Process Theories in Social Psychology. Guilford, New York.

[19] Anderson, J.C. and Gerbing, D.W. (1988) Structural Equation Modeling in Practice: A Review and Recommended Two-Step Approach. Psychological Bulletin, 103, 411-423. http://dx.doi.org/10.1037/0033-2909.103.3.411

[20] Fornell, C. and Larcker, D.F. (1981) Evaluating Structural Equation Models with Unobservable Variables and Measurement Error. Journal of Marketing Research, 18, 39-50. http://dx.doi.org/10.2307/3151312 
Scientific Research Publishing (SCIRP) is one of the largest Open Access journal publishers. It is currently publishing more than 200 open access, online, peer-reviewed journals covering a wide range of academic disciplines. SCIRP serves the worldwide academic communities and contributes to the progress and application of science with its publication.

Other selected journals from SCIRP are listed as below. Submit your manuscript to us via either submit@scirp.org or Online Submission Portal.
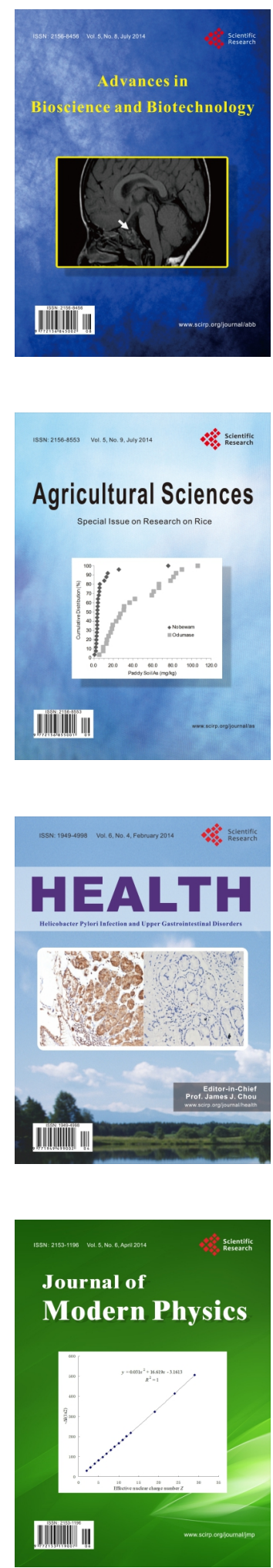
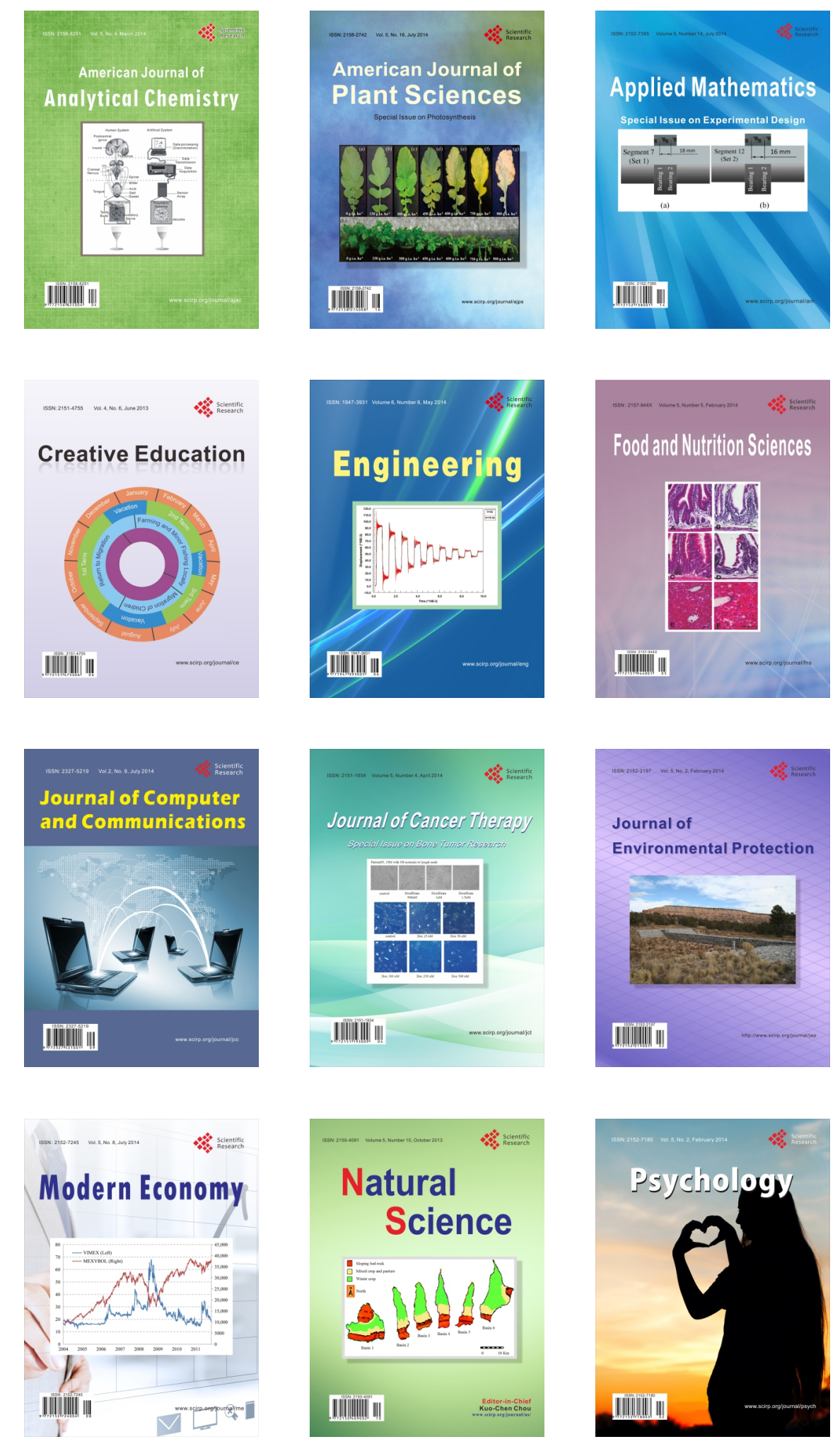